\title{
Reclassification of Xylanibacter oryzae Ueki et al. 2006 as Prevotella oryzae comb. nov., with an emended description of the genus Prevotella
}

\author{
Mitsuo Sakamoto and Moriya Ohkuma \\ Microbe Division/Japan Collection of Microorganisms, RIKEN BioResource Center, Wako, \\ Saitama 351-0198, Japan
}

Correspondence

Mitsuo Sakamoto

sakamoto@jcm.riken.jp
A strictly anaerobic, xylanolytic bacterium, strain $\mathrm{KB}^{\mathrm{T}}$, was isolated from rice-plant residue in flooded anoxic ricefield soil in Japan (Ueki et al., 2006). This bacterium was phylogenetically related to members of the genus Prevotella (about $89 \%$ 16S rRNA gene sequence similarity). The genus Prevotella in the phylum Bacteroidetes comprises a variety of species and 16S rRNA gene sequence similarities among its members range from 85.6 to $97.7 \%$ (mean \pm SEM $89.6 \pm 0.1 \%$ ) (Sakamoto \& Ohkuma, 2010). Although strain $\mathrm{KB} 3^{\mathrm{T}}$ could have been assigned to the genus Prevotella from the viewpoint of sequence similarity, Ueki et al. (2006) proposed a novel species in a new genus, Xylanibacter oryzae, on the basis of phylogenetic, ecological, physiological and chemotaxonomic characteristics. The creation of the genus Xylanibacter particularly depended on ecological differences: members of the genus Prevotella have been isolated mainly from the oral cavity (some are associated with periodontitis) and also from, for example, the genito-urinary tract, vagina and cervix, which are environments very different from that in which X. oryzae was found. Of the members of the genus Prevotella, Prevotella paludivivens is the only species derived from a natural habitat, i.e. plant residue and rice roots in irrigated rice-field soil, similarly to $X$. oryzae (Ueki et al., 2007).

Recently, hsp60 has been found to be an alternative phylogenetic marker for the identification and

The GenBank/EMBL/DDBJ accession numbers for the 16S rRNA gene sequences of Prevotella oryzae comb. nov. JCM $13648^{\top}$ and JCM 13649 are $\mathrm{AB} 588018$ and $\mathrm{AB} 588019$ and for the $h s p 60$ sequences are $\mathrm{AB675483}$ and $\mathrm{AB675484}$, respectively. classification of a broad range of Gram-negative anaerobic rods, including the genera Bacteroides, Barnesiella, Butyricimonas, Odoribacter, Parabacteroides, Paraprevotella, Porphyromonas, Prevotella and Tannerella (Kitahara et al., 2011, 2012; Sakamoto \& Ohkuma, 2010, 2012; Sakamoto et al., 2010a, b). In this study, the taxonomic position of $X$. oryzae was determined using $h s p 60$ and $16 \mathrm{~S}$ rRNA gene sequences.

A total of 109 strains of 108 species in 10 genera were obtained from the Japan Collection of Microorganisms (JCM), RIKEN BioResource Center, Wako, Japan. These belonged to the genera Bacteroides (38 strains from 38 species), Barnesiella (two strains from two species), Butyricimonas (two strains from two species), Odoribacter (two strains from two species), Parabacteroides (five strains from five species), Paraprevotella (two strains from two species), Porphyromonas (17 strains from 17 species), Prevotella (38 strains from 38 species), Tannerella (one strain from one species) and Xylanibacter (two strains from one species). The strains were maintained according to the JCM Online Catalogue (http://www.jcm. riken.jp/JCM/catalogue.shtml) except for X. oryzae JCM $13648^{\mathrm{T}}$ and JCM 13649 and $P$. paludivivens JCM $13650^{\mathrm{T}}$, which grew poorly on the medium specified by the depositor, PY4S agar (Ueki et al., 2006, 2007); therefore, these strains were maintained on Columbia blood agar (Oxoid) supplemented with $5 \%(\mathrm{v} / \mathrm{v})$ horse blood.

The physiological and biochemical characteristics of $X$. oryzae JCM $13648^{\mathrm{T}}$ and JCM 13649 were determined in duplicate using the API 20A anaerobe test kit and the Rapid ID 32A anaerobe identification kit, respectively (bioMérieux), according to the manufacturer's 
instructions. Fatty acid methyl esters of $X$. oryzae JCM $13648^{\mathrm{T}}$ and JCM 13649 were obtained from about $40 \mathrm{mg}$ wet cells grown on Columbia blood agar at $30{ }^{\circ} \mathrm{C}$ for $72 \mathrm{~h}$ by saponification, methylation and extraction, using minor modifications (Kuykendall et al., 1988) of the method of Miller (1982). The cellular fatty acid compositions were determined using the Sherlock Microbial Identification System version 2.99B (MIDI) with the BHIBLA database (version 3.80). Peaks were automatically integrated, fatty acids were identified by equivalent chain-lengths and percentages of the total peak area were calculated. External calibration was done using MIDI calibration mixture 1 (methyl esters of straight-chain saturated fatty acids with length 9-20 carbons and with five hydroxy acids). Isoprenoid quinones were extracted as described by Komagata \& Suzuki (1988) and analysed by HPLC with a Cosmosil $5 \mathrm{C}_{18}$ column $(4.6 \times 150 \mathrm{~mm}$; NacalaiTesque). The elution solvent was methanol/2-propanol $(2: 1, \mathrm{v} / \mathrm{v})$.

Bacterial genomic DNA was extracted using a High Pure PCR Template Preparation kit (Roche Applied Science). The 16S rRNA sequence was determined as described previously (Sakamoto et al., 2002). The partial hsp60 sequence (558 bp) was determined as described previously (Sakamoto \& Ohkuma, 2010; Sakamoto et al., 2010b). Sequences were aligned using CLUSTAL X version 2.0.12 (Larkin et al., 2007) and corrected by manual inspection. Nucleotide substitution rates $\left(K_{\text {nuc }}\right)$ were calculated (Kimura, 1980) after gaps and unknown bases were eliminated. The phylogenetic tree was constructed by the neighbour-joining algorithm (Saitou \& Nei, 1987). Maximum-likelihood analysis was performed using PhyML version 3.0 (Guindon \& Gascuel, 2003), with the optimal model of nucleotide substitution estimated using jModelTest 0.1.1 (Posada, 2008) and the Akaike information criterion. The model selected was GTR $+\mathrm{I}+\mathrm{G}$ for both genes. Maximum-likelihood analysis was also performed with raxmlGUI 0.95 using the GTRGAMMAI model (Silvestro \& Michalak, 2010; Stamatakis, 2006). To estimate the confidence of tree topologies, bootstrap resampling analysis (Felsenstein, 1985) was performed using 1000 replications for both algorithms. The ShimodairaHasegawa test (Shimodaira \& Hasegawa, 1999) and the approximately unbiased test (Shimodaira, 2002) in CONSEL $0.1 \mathrm{i}$ (Shimodaira \& Hasegawa, 2001) were used for statistical comparisons of alternative trees of interest. The significance level was $<0.05$.

Cells of X. oryzae JCM $13648^{\mathrm{T}}$ and JCM 13649 were obligately anaerobic, non-spore-forming, non-motile, Gramnegative, short to filamentous rods. Cells on Columbia blood agar were $0.8-1.0 \mu \mathrm{m}$ wide and variable in length, mostly 2.0-15.0 $\mu \mathrm{m}$. Colonies on Columbia blood agar after $72 \mathrm{~h}$ at $30{ }^{\circ} \mathrm{C}$ were $1-2 \mathrm{~mm}$ in diameter, circular, entire, slightly convex, smooth, white-greyish and translucent. The X. oryzae strains grew well on Columbia blood agar, similarly to members of the genus Prevotella. The phenotypic and biochemical characteristics of the two $X$. oryzae strains were the same and are given in the species description.
Table 1. Cellular fatty acid compositions of Prevotella oryzae comb. nov.

Strains: $1, \mathrm{~KB}^{\mathrm{T}}$ (data from Ueki et al., 2006); 2, JCM $13648^{\mathrm{T}}$ (this study); 3, JCM 13649 (this study). tr, Trace (<1\%); -, not detected.

\begin{tabular}{|c|c|c|c|}
\hline Fatty acid (\%) & 1 & 2 & 3 \\
\hline \multicolumn{4}{|l|}{ Saturated straight-chain } \\
\hline $\mathrm{C}_{9: 0}$ & - & $\operatorname{tr}$ & - \\
\hline $\mathrm{C}_{10: 0}$ & - & $\operatorname{tr}$ & - \\
\hline $\mathrm{C}_{11: 0}$ & - & $\operatorname{tr}$ & - \\
\hline $\mathrm{C}_{12: 0}$ & - & $\operatorname{tr}$ & - \\
\hline $\mathrm{C}_{13: 0}$ & - & $\operatorname{tr}$ & - \\
\hline $\mathrm{C}_{14: 0}$ & - & $\operatorname{tr}$ & $\operatorname{tr}$ \\
\hline $\mathrm{C}_{15: 0}$ & 4.7 & 1.0 & 2.2 \\
\hline $\mathrm{C}_{16: 0}$ & 3.1 & 4.4 & 6.4 \\
\hline $\mathrm{C}_{17: 0}$ & - & $\operatorname{tr}$ & - \\
\hline $\mathrm{C}_{18: 0}$ & - & $\operatorname{tr}$ & $\operatorname{tr}$ \\
\hline $\mathrm{C}_{19: 0}$ & - & $\operatorname{tr}$ & - \\
\hline $\mathrm{C}_{20: 0}$ & - & $\operatorname{tr}$ & - \\
\hline \multicolumn{4}{|c|}{ Unsaturated straight-chain } \\
\hline $\mathrm{C}_{13: 1} \omega 1 c$ & - & $\operatorname{tr}$ & 1.0 \\
\hline $\mathrm{C}_{16: 1} \omega 7 c$ & - & $\operatorname{tr}$ & - \\
\hline $\mathrm{C}_{18: 2} \omega 6,9 c$ & - & 5.3 & 7.7 \\
\hline $\mathrm{C}_{18: 1} \omega 9 c$ & - & 2.9 & 4.0 \\
\hline \multicolumn{4}{|l|}{ Hydroxy } \\
\hline iso- $\mathrm{C}_{15: 0} 3-\mathrm{OH}$ & - & $\operatorname{tr}$ & $\operatorname{tr}$ \\
\hline anteiso- $\mathrm{C}_{15: 0} 3-\mathrm{OH}$ & - & $\operatorname{tr}$ & - \\
\hline $\mathrm{C}_{15: 0} 3-\mathrm{OH}$ & - & - & $\operatorname{tr}$ \\
\hline $\mathrm{C}_{16: 0} 3-\mathrm{OH}$ & - & 1.7 & 2.4 \\
\hline iso- $\mathrm{C}_{17: 0} 3-\mathrm{OH}$ & 21.8 & 9.0 & 6.7 \\
\hline anteiso- $\mathrm{C}_{17: 0} 3-\mathrm{OH}$ & 3.7 & 3.9 & 3.2 \\
\hline $\mathrm{C}_{17: 0} 3-\mathrm{OH}$ & 5.2 & 1.6 & $\operatorname{tr}$ \\
\hline \multicolumn{4}{|c|}{ Saturated branched-chain } \\
\hline iso- $\mathrm{C}_{13: 0}$ & - & 1.1 & 1.3 \\
\hline iso- $\mathrm{C}_{14: 0}$ & - & $\operatorname{tr}$ & $\operatorname{tr}$ \\
\hline iso- $\mathrm{C}_{15: 0}$ & 3.7 & 4.2 & 4.3 \\
\hline iso- $\mathrm{C}_{16: 0}$ & - & $\operatorname{tr}$ & - \\
\hline iso- $\mathrm{C}_{17: 0}$ & 3.3 & $\operatorname{tr}$ & $\operatorname{tr}$ \\
\hline anteiso- $\mathrm{C}_{13: 0}$ & - & $\operatorname{tr}$ & $\operatorname{tr}$ \\
\hline anteiso- $\mathrm{C}_{15: 0}$ & 42.2 & 49.8 & 50.2 \\
\hline anteiso- $\mathrm{C}_{17: 0}$ & - & $\operatorname{tr}$ & $\operatorname{tr}$ \\
\hline \multicolumn{4}{|l|}{ Summed features ${ }^{*}$} \\
\hline 3 & - & 5.5 & 4.0 \\
\hline 9 & - & 1.0 & 1.0 \\
\hline
\end{tabular}

* Summed features represent two or three fatty acids that cannot be separated by the Microbial Identification System. Summed feature 3 consisted of equivalent chain-length 13.570 and/or iso- $\mathrm{C}_{15: 0}$ alde. Summed feature 9 consisted of iso- $\mathrm{C}_{16: 0} 3-\mathrm{OH}$ and/or equivalent chain-length 17.157 .

The major cellular fatty acids of X. oryzae JCM $13648^{\mathrm{T}}$ and JCM 13649 determined in this study were anteiso- $\mathrm{C}_{15: 0}$ and iso- $\mathrm{C}_{17: 0} 3-\mathrm{OH}$, which are as described for $X$. oryzae $\mathrm{KB}^{\mathrm{T}}$ by Ueki et al. (2006), although there were differences in the proportions (Table 1). The major menaquinones of strains X. oryzae JCM $13648^{\mathrm{T}}$ and JCM 13649 were MK-12 


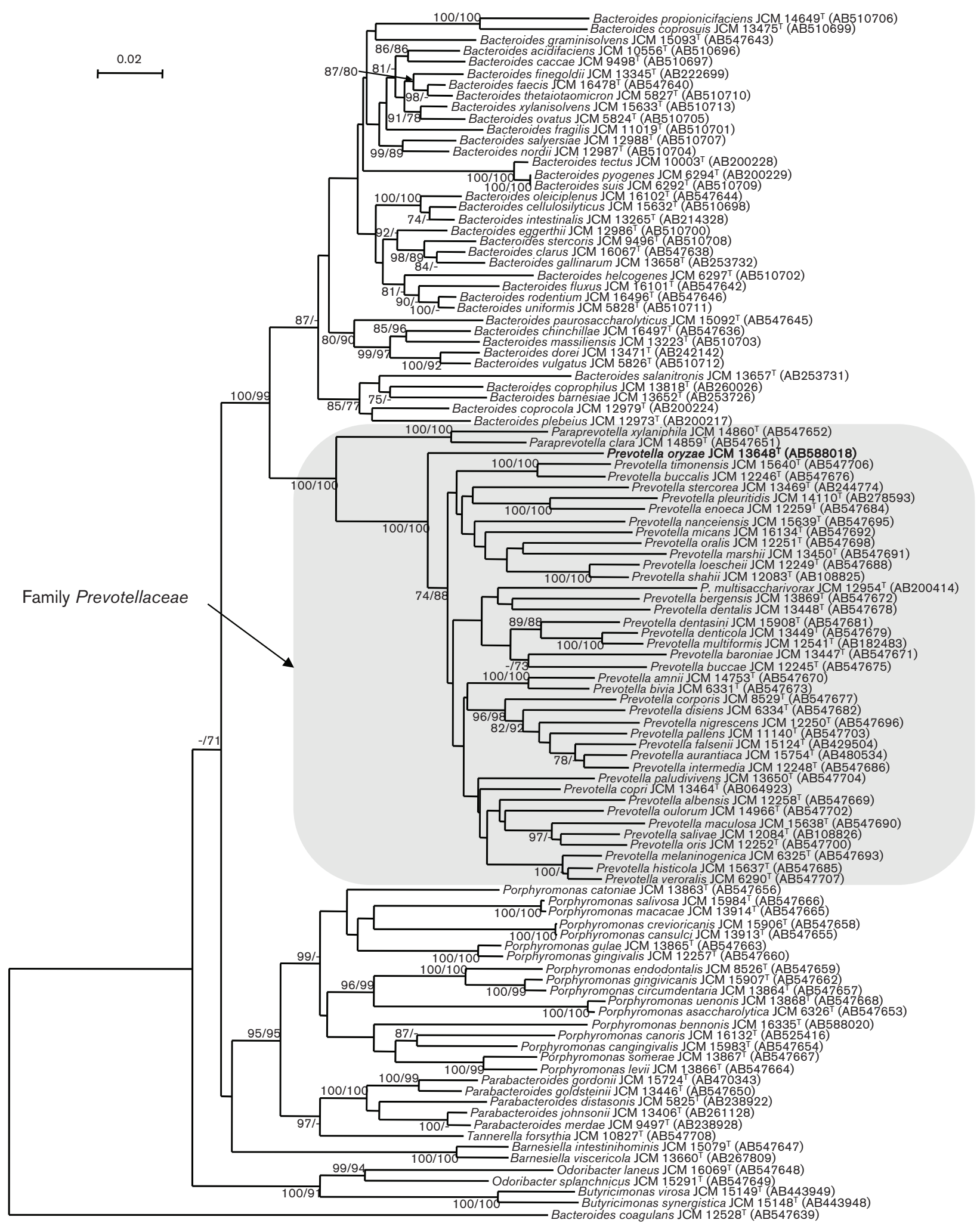

Fig. 1. Neighbour-joining phylogenetic tree based on 16S rRNA gene sequences showing the relationships between 108 type strains of species of Gram-negative anaerobic rods. Bootstrap values ( $>70 \%)$ based on 1000 replicates are shown at branch nodes for neighbour-joining and maximum-likelihood, respectively. Bar, 0.02 substitutions per nucleotide position. 


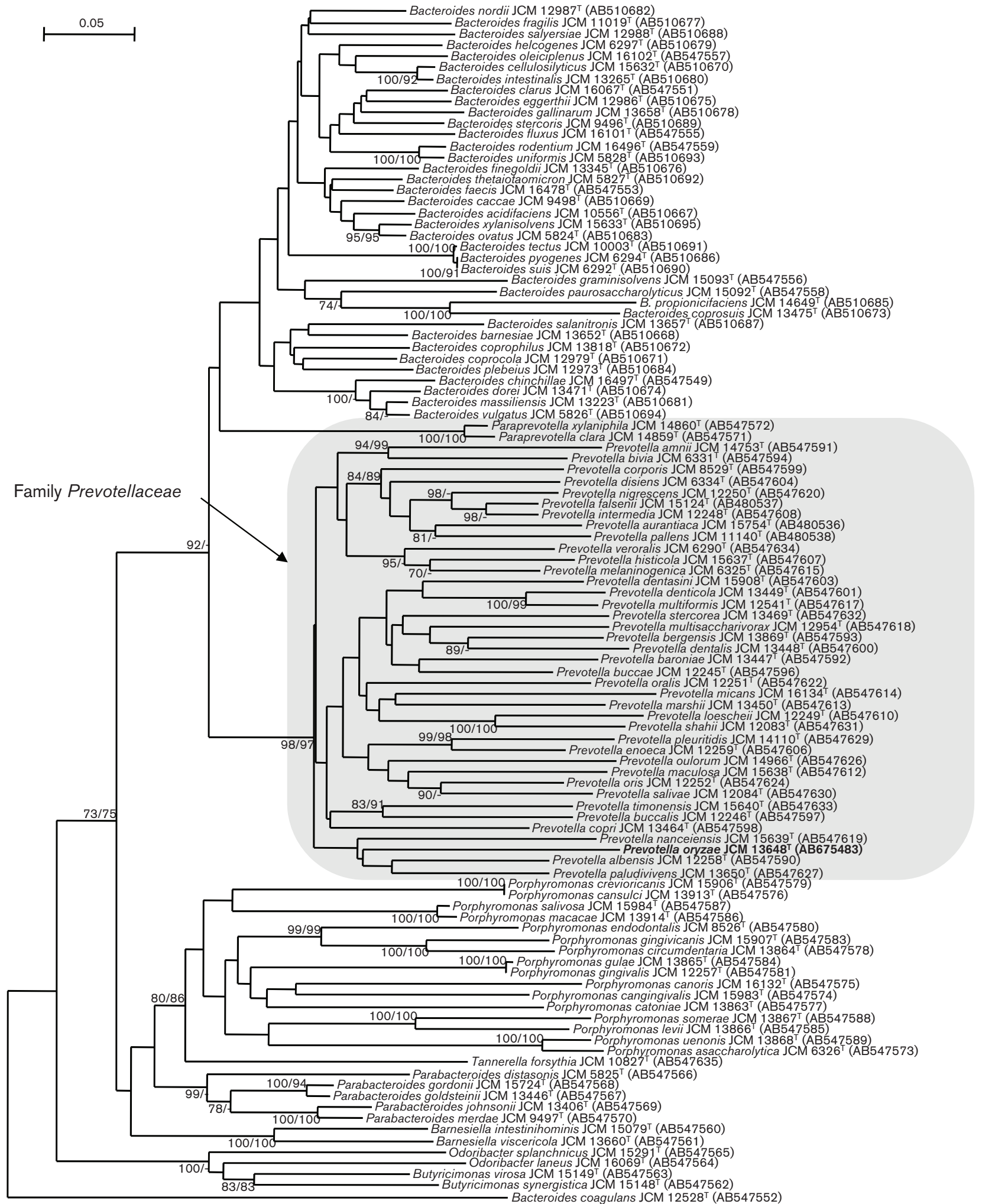

Fig. 2. Neighbour-joining phylogenetic tree based on $h s p 60$ sequences showing the relationships between 107 type strains of species of Gram-negative anaerobic rods. Bootstrap values ( $>70 \%)$ based on 1000 replicates are shown at branch nodes for neighbour-joining and maximum-likelihood, respectively. Bar, 0.05 substitutions per nucleotide position. 
(19\%) and MK-13 (77\%), which are in agreement with Ueki et al. (2006). It should be noted that X. oryzae is phenotypically similar to members of the genus Prevotella (Shah \& Collins, 1990).

Approximately $1500 \mathrm{bp}$ of the $16 \mathrm{~S}$ rRNA gene sequence was determined for each strain. For the phylogenetic analysis, $1427 \mathrm{bp}$ was used. X. oryzae JCM $13648^{\mathrm{T}}$ and JCM 13649 exhibited $99.7 \% 16 \mathrm{~S}$ rRNA gene sequence similarity with each other. X. oryzae JCM $13648^{\mathrm{T}}$ formed a distinct line of descent with high bootstrap support (100\%) (Fig. 1). X. oryzae JCM $13648^{\mathrm{T}}$ and all members of the genus Prevotella formed a single cluster with high bootstrap support (100\%) and were phylogenetically distinct from the two members of the genus Paraprevotella (Morotomi et al., 2009). In the hsp60 sequence analysis, X. oryzae JCM $13648^{\mathrm{T}}$ was located within the genus Prevotella although the bootstrap values were low ( $<70 \%$; Fig. 2). In the gyrB sequence analysis (data not shown), X. oryzae JCM $13648^{\mathrm{T}}$ was also located within the genus Prevotella. These findings show that $X$. oryzae is not independent of the genus Prevotella and our views on the matter were supported by statistical tests with respect to the family Prevotellaceae. In the $16 \mathrm{~S}$ rRNA gene sequence analysis, the log-likelihood differences between the optimal tree and the alternative trees in which $X$. oryzae nested within the genus Prevotella were not significant $(P>0.05)$. On the other hand, in the $h s p 60$ sequence analysis, if $X$. oryzae was moved to outside the genus Prevotella, the log-likelihood differences were significant (approximately unbiased test $P=0.018$, Shimodaira-Hasegawa test $P=0.015$ ). These results suggest that $X$. oryzae is monophyletic with the other members of the genus Prevotella. In addition, almost all of the $16 \mathrm{~S}$ rRNA gene signature nucleotides reported for Prevotella species (Paster et al., 1994) were present in $X$. oryzae: only the nucleotides T/G at positions $600 / 638$ were different in $X$. oryzae, which had G/T at these positions.

On the basis of the above-mentioned findings, we propose that X. oryzae should be reclassified as Prevotella oryzae comb. nov. An emended description of the genus Prevotella is also provided. The name of the family Prevotellaceae, which was proposed in the accepted version of this manuscript, was validly published (Krieg, 2011) after acceptance but before publication of this manuscript.

\section{Emended description of the genus Prevotella Shah and Collins 1990}

The description is as given by Shah \& Collins (1990) and Willems \& Collins (1995) with the following modifications. The optimum temperature for growth is 30 or $37{ }^{\circ} \mathrm{C}$. Utilizes various sugars, including xylan, and produces acetate, propionate and succinate as major fermentation end products; occasionally, lower levels of iso-butyrate, iso-valerate, lactate or malate are produced. Respiratory menaquinones, principally MK-10 to MK-13 or MK-11( $\left.\mathrm{H}_{2}\right)$ to MK-13 $\left(\mathrm{H}_{2}\right)$, may or may not be present. Habitats are mammals or rice-plant residue (plant stubble and roots). The type species is Prevotella melaninogenica.

\section{Description of Prevotella oryzae Ueki et al. 2006} comb. nov.

Prevotella oryzae (o.ry'za.e. L. fem. n. oryza rice, the genus name of rice; L. gen. n. oryzae from/of rice or rice plants, referring to the rice-plant residue from which the type strain was isolated).

Basonym: Xylanibacter oryzae Ueki et al. 2006.

The description is as given by Ueki et al. (2006) with the following modifications. Cells on Columbia blood agar are $0.8-1.0 \mu \mathrm{m}$ wide and variable in length, mostly 2.0$15.0 \mu \mathrm{m}$. Colonies on Columbia blood agar after $72 \mathrm{~h}$ at $30{ }^{\circ} \mathrm{C}$ under anaerobic conditions are $1-2 \mathrm{~mm}$ in diameter, circular, entire, slightly convex, smooth, white-greyish and translucent. Acid is produced from raffinose, but not from D-sorbitol and sucrose [acid production from sucrose is given as positive in the description of Ueki et al. (2006)]. Catalase is not produced. With Rapid ID 32A, positive for $\alpha$-galactosidase, $\beta$-galactosidase, $\alpha$-glucosidase, $\beta$-glucosidase, $\alpha$-arabinosidase, leucyl glycine arylamidase, alanine arylamidase and fermentation of mannose and raffinose, but negative for urease, arginine dihydrolase, 6-phospho- $\beta$ galactosidase, $\beta$-glucuronidase, $\beta$ - $N$-acetylglucosaminidase, glutamic acid decarboxylase, $\alpha$-fucosidase, nitrate reduction, indole production, alkaline phosphatase, arginine arylamidase, proline arylamidase, phenylalanine arylamidase, leucine arylamidase, pyroglutamic acid arylamidase, tyrosine arylamidase, glycine arylamidase, histidine arylamidase, glutamyl glutamic acid arylamidase and serine arylamidase.

The type strain, $\mathrm{KB}^{\mathrm{T}}\left(=\mathrm{JCM} 13648^{\mathrm{T}}=\mathrm{DSM} 17970^{\mathrm{T}}\right)$, was isolated from stubble and roots of rice-plant residue in anoxic rice-field soil in Japan.

\section{Acknowledgements}

We thank Ms Natsuko Suzuki and Ms Misako Matsuda for their technical assistance. This work was supported by the Institute for Fermentation, Osaka, Japan (grant number 2009-2011) and by a Grant-in-Aid for Scientific Research from the Japan Society for the Promotion of Science (grant number 23580126) to M.S.

\section{References}

Felsenstein, J. (1985). Confidence limits of phylogenies: an approach using the bootstrap. Evolution 39, 783-791.

Guindon, S. \& Gascuel, O. (2003). A simple, fast, and accurate algorithm to estimate large phylogenies by maximum likelihood. Syst Biol 52, 696-704.

Kimura, M. (1980). A simple method for estimating evolutionary rates of base substitutions through comparative studies of nucleotide sequences. J Mol Evol 16, 111-120.

Kitahara, M., Tsuchida, S., Kawasumi, K., Amao, H., Sakamoto, M., Benno, Y. \& Ohkuma, M. (2011). Bacteroides chinchillae sp. nov. and Bacteroides rodentium sp. nov., isolated from chinchilla (Chinchilla lanigera) faeces. Int J Syst Evol Microbiol 61, 877-881.

Kitahara, M., Sakamoto, M., Tsuchida, S., Kawasumi, K., Amao, H., Benno, Y. \& Ohkuma, M. (2012). Bacteroides stercorirosoris sp. nov. 
and Bacteroides faecichinchillae sp. nov., isolated from chinchilla (Chinchilla lanigera) faeces. Int J Syst Evol Microbiol 62, 1145-1150.

Komagata, K. \& Suzuki, K. (1988). Lipid and cell-wall analysis in bacterial systematics. Methods Microbiol 19, 161-207.

Krieg, N. R. (2011). Family V. Prevotellaceae fam. nov. In Bergey's Manual of Systematic Bacteriology, 2nd edn, vol. 4, p. 85. Edited by N. R. Krieg, J. T. Staley, D. R. Brown, B. P. Hedlund, B. J. Paster, N. L. Ward, W. Ludwig \& W. B. Whitman. New York: Springer.

Kuykendall, L. D., Roy, M. A., O’Neill, J. J. \& Devine, T. E. (1988). Fatty acids, antibiotic resistance, and deoxyribonucleic acid homology groups of Bradyrhizobium japonicum. Int J Syst Bacteriol 38, 358-361.

Larkin, M. A., Blackshields, G., Brown, N. P., Chenna, R., McGettigan, P. A., McWilliam, H., Valentin, F., Wallace, I. M., Wilm, A. \& other authors (2007). CLUSTAL W and CLUSTAL_X version 2.0. Bioinformatics 23, 2947-2948.

Miller, L. T. (1982). Single derivatization method for routine analysis of bacterial whole-cell fatty acid methyl esters, including hydroxy acids. J Clin Microbiol 16, 584-586.

Morotomi, M., Nagai, F., Sakon, H. \& Tanaka, R. (2009). Paraprevotella clara gen. nov., sp. nov. and Paraprevotella xylaniphila sp. nov., members of the family 'Prevotellaceae' isolated from human faeces. Int J Syst Evol Microbiol 59, 1895-1900.

Paster, B. J., Dewhirst, F. E., Olsen, I. \& Fraser, G. J. (1994). Phylogeny of Bacteroides, Prevotella, and Porphyromonas spp. and related bacteria. J Bacteriol 176, 725-732.

Posada, D. (2008). jModelTest: phylogenetic model averaging. $\mathrm{Mol}$ Biol Evol 25, 1253-1256.

Saitou, N. \& Nei, M. (1987). The neighbor-joining method: a new method for reconstructing phylogenetic trees. Mol Biol Evol 4, 406425.

Sakamoto, M. \& Ohkuma, M. (2010). Usefulness of the $h s p 60$ gene for the identification and classification of Gram-negative anaerobic rods. J Med Microbiol 59, 1293-1302.

Sakamoto, M. \& Ohkuma, M. (2012). Bacteroides sartorii is an earlier heterotypic synonym of Bacteroides chinchillae and has priority. Int $J$ Syst Evol Microbiol 62, 1241-1244.

Sakamoto, M., Suzuki, M., Umeda, M., Ishikawa, I. \& Benno, Y. (2002). Reclassification of Bacteroides forsythus (Tanner et al. 1986) as Tannerella forsythensis corrig., gen. nov., comb. nov. Int J Syst Evol Microbiol 52, 841-849.
Sakamoto, M., Suzuki, N. \& Okamoto, M. (2010a). Prevotella aurantiaca sp. nov., isolated from the human oral cavity. Int J Syst Evol Microbiol 60, 500-503.

Sakamoto, M., Suzuki, N. \& Benno, Y. (2010b). hsp60 and 16S rRNA gene sequence relationships among species of the genus Bacteroides with the finding that Bacteroides suis and Bacteroides tectus are heterotypic synonyms of Bacteroides pyogenes. Int J Syst Evol Microbiol 60, 2984-2990.

Shah, H. N. \& Collins, D. M. (1990). Prevotella, a new genus to include Bacteroides melaninogenicus and related species formerly classified in the genus Bacteroides. Int J Syst Bacteriol 40, 205-208.

Shimodaira, H. (2002). An approximately unbiased test of phylogenetic tree selection. Syst Biol 51, 492-508.

Shimodaira, H. \& Hasegawa, M. (1999). Multiple comparisons of log-likelihoods with applications to phylogenetic inference. Mol Biol Evol 16, 1114-1116.

Shimodaira, H. \& Hasegawa, M. (2001). CONSEL: for assessing the confidence of phylogenetic tree selection. Bioinformatics 17, 12461247.

Silvestro, D. \& Michalak, I. (2010). raxmlGUI: a graphical front-end for RAxML. Available at http://sourceforge.net/projects/raxmlgui/.

Stamatakis, A. (2006). RAxML-VI-HPC: maximum likelihood-based phylogenetic analyses with thousands of taxa and mixed models. Bioinformatics 22, 2688-2690.

Ueki, A., Akasaka, H., Suzuki, D., Hattori, S. \& Ueki, K. (2006). Xylanibacter oryzae gen. nov., sp. nov., a novel strictly anaerobic, Gram-negative, xylanolytic bacterium isolated from rice-plant residue in flooded rice-field soil in Japan. Int J Syst Evol Microbiol 56, 22152221.

Ueki, A., Akasaka, H., Satoh, A., Suzuki, D. \& Ueki, K. (2007). Prevotella paludivivens sp. nov., a novel strictly anaerobic, Gramnegative, hemicellulose-decomposing bacterium isolated from plant residue and rice roots in irrigated rice-field soil. Int J Syst Evol Microbiol 57, 1803-1809.

Willems, A. \& Collins, M. D. (1995). 16S rRNA gene similarities indicate that Hallella seregens (Moore and Moore) and Mitsuokella dentalis (Haapsalo et al.) are genealogically highly related and are members of the genus Prevotella: emended description of the genus Prevotella (Shah and Collins) and description of Prevotella dentalis comb. nov. Int J Syst Bacteriol 45, 832-836. 